\title{
Comparison of Intrathecal Dexmedetomidine and Nalbuphine as an Adjuvant in Hyperbaric Bupivacaine for Saddle Block and Postoperative Analgesia in Patients Undergoing Perianal Surgeries
}

\author{
Bhargav Vishnu Gantasala ${ }^{1}$, Amol Singam², Saranya Rallabhandi3 \\ Kashish Chaubey ${ }^{4}$ Pallavi Deulkar ${ }^{5}$, Ayush Pal Bansal ${ }^{6}$
}

\begin{abstract}
${ }^{1}$ Department of Anaesthesiology, JNMC, DMIMS, Sawangi, Wardha, Maharashtra, India. ${ }^{2}$ Department of Anaesthesiology, JNMC, DMIMS, Sawangi, Wardha, Maharashtra, India. ${ }^{3}$ Department of Anaesthesiology, JNMC, DMIMS, Sawangi, Wardha, Maharashtra, India. ${ }^{4}$ Department of Anaesthesiology, JNMC, DMIMS, Sawangi, Wardha, Maharashtra, India. ${ }^{5}$ Department of Anaesthesiology, JNMC, DMIMS, Sawangi, Wardha, Maharashtra, India. ${ }^{6}$ Department of Anaesthesiology, JNMC, DMIMS, Sawangi, Wardha, Maharashtra, India.
\end{abstract}

\section{ABSTRACT}

\section{BACKGROUND}

Saddle block is the most commonly used anaesthetic technique for perianal surgeries in adults. Perianal surgeries under saddle block are considered as day care surgeries. Major disadvantage is that the low volume of spinally given drug won't prolong duration of postoperative analgesia. Inj. Dexmedetomidine ( $\alpha_{2}$-Adrenoceptor agonist) and Inj. Nalbuphine (opioid agonist-antagonist) were studied as an adjuvant as to whether they increase the duration of post-operative analgesia. Secondary objectives of this study were to compare hemodynamic stability and side effects among Inj. Dexmedetomidine and Inj. Nalbuphine.

\section{METHODS}

A total of 60 patients with American Society of Anaesthesiologist physical Status I and II scheduled for elective perianal surgeries were randomly allocated into two equal groups in this randomized prospective comparative study. Group D received $0.5 \%$ hyperbaric bupivacaine $0.8 \mathrm{~mL}+5 \mathrm{mcg}$ dexmedetomidine and group $\mathrm{N}$ received $0.5 \%$ hyperbaric bupivacaine $0.8 \mathrm{~mL}+0.6 \mathrm{mg}$ nalbuphine. Onset and duration of sensory and motor blockade, and duration of analgesia were recorded. Post-operative analgesic consumption and side effects were studied for 24 hours. Statistical analysis was done by using descriptive and inferential statistics using Chi- square test and Student's t-test.

\section{RESULTS}

Demographic characteristics, duration of surgery, onset of sensory and motor block were comparable. Duration of analgesia was $320.26 \pm 89.52 \mathrm{~min}$ for dexmedetomidine (D) whereas it was $222.23 \pm 25.43 \mathrm{~min}$ for nalbuphine (N) with a $P$ value of $<0.05$. No side effects were noted.

\section{CONCLUSION}

A dose of 5 mcg dexmedetomidine as an adjuvant seems to be optimal for providing postoperative analgesia with better hemodynamic stability.

\section{KEY WORDS}

Dexmedetomidine, Nalbuphine, Saddle Block, Perianal Surgeries, Hyperbaric Bupivacaine
Corresponding Author:

Dr. Amol Singam,

Professor and HOD,

Department of Anaesthesiology, AVBRH, Datta Meghe Institute of Medical Sciences, Sawangi-442001, Wardha, Maharashtra, India.

E-mail: dramolsingam@gmail.com

DOI: $10.14260 /$ jemds/2020/442

How to Cite This Article:

Gantasala BV, Singam A, Rallabhandi S, et al. Comparison of intrathecal dexmedetomidine and nalbuphine as an adjuvant in hyperbaric bupivacaine for saddle block and postoperative analgesia in patients undergoing perianal surgeries. $J$ Evolution Med. Dent. Sci. 2020;9(29):20282033, DOI: 10.14260/jemds/2020/442

Submission 28-04-2020,

Peer Review 11-06-2020,

Acceptance 18-06-2020,

Published 20-07-2020.

Copyright (C) 2020 JEMDS. This is an open access article distributed under Creative Commons Attribution License [Attribution 4.0 International (CC BY 4.0)] 


\section{BACKGROUND}

Saddle block is the most commonly used anaesthetic technique for perianal surgeries in adults. ${ }^{[1]}$ Perianal surgeries under saddle block are considered as day care surgeries. Low volume spinal drug can limit the sympathetic block level in sitting position after administering the drug spinally and bring rapid recovery from anaesthesia with minimal side effects along with early ambulation.[2],[3] Hyperbaric bupivacaine is most commonly preferred for saddle block but major disadvantage is low volume of spinally given drug won't prolong duration of postoperative analgesia. ${ }^{[4]}$

Therefore, research for the drug that may subside the postoperative pain with lesser side effects is required. Wide variety of adjuvants have been used to prolong post-operative analgesia, along with the local anaesthetic drug. These are opioids, clonidine, dexmedetomidine, nalbuphine, and ketamine.[5]

Dexmedetomidine is the next generation $\alpha_{2}$ agonist with highly selective $\alpha_{2}$-Adrenoceptor agonist. It provides hemodynamic stability to the patient during surgery along with intraoperative analgesia and also provide postoperative analgesia with fewer side effects. It also provides more sedation and lesser irritability. Side effects of dexmedetomidine are hemodynamic effects like bradycardia and hypotension.[5],[6] It has been used for sedation and analgesia for many years. ${ }^{[6]}$

Nalbuphine belongs to opioid family of phenanthrene series. It is a semi-synthetic opioid with agonistic action at kappa receptor and antagonistic action at mu receptor. ${ }^{[7]}$ It provides analgesia and sedation due to the agonistic action at kappa receptor and minimal side effects due to antagonistic action at mu receptor.[8] Therefore, nalbuphine produce minimal side effects like nausea, vomiting and pruritus compared to morphine.[9] It also does not cause hemodynamic instability and respiratory depression.[10] It does not cause any addiction unlike other opioids like morphine, fentanyl etc., due to its antagonistic action at $\mathrm{mu}$ receptor. Inj. Dexmedetomidine and Inj. Nalbuphine were studied as adjuvants whether they increase the duration of postoperative analgesia.

Primary objective of this study was to compare Inj. Dexmedetomidine and Inj. Nalbuphine as adjuvants to Inj. Bupivacaine for duration of postoperative analgesia. Secondary objectives were to compare the hemodynamic stability and side effects associated with these two adjuvants.

\section{METHODS}

The present randomised prospective comparative study was carried out after the approval of Ethics and Screening Committee. The study was conducted from April 2018 to May 2019. Written informed consent was taken from the patients during pre-anaesthetic evaluation. Sixty patients from either gender, aged between 20 - 60 years with ASA Grade I and II who were scheduled for perianal surgeries like lateral sphincterotomy, haemorrhoidectomy, anal fistula and fissurectomy under saddle block, were selected randomly. [table/Fig. 1].

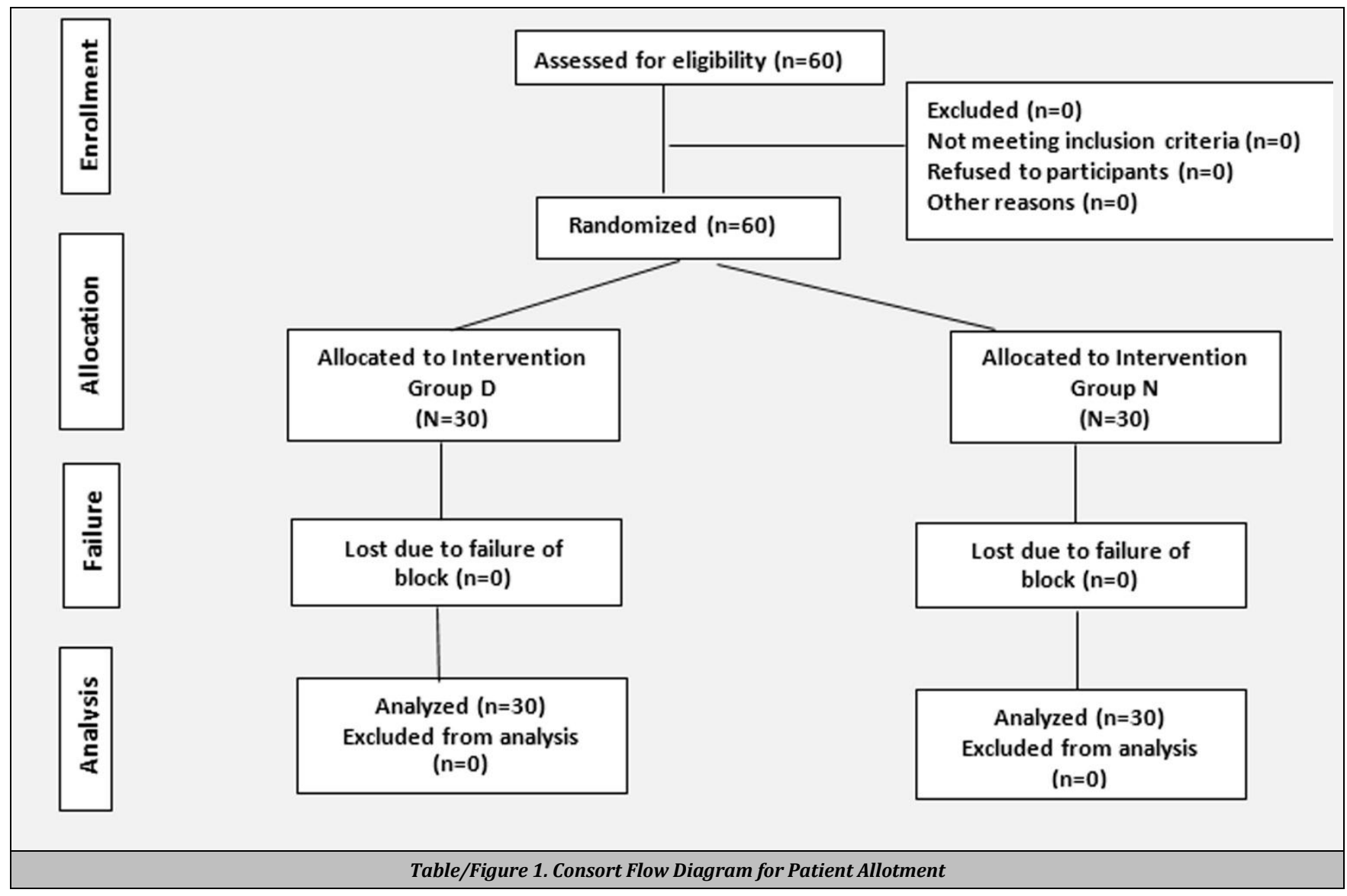


Patient's refusal, pregnancy, patients with spinal abnormality, history of spine surgery, bleeding diathesis, neurological diseases, infection at site of lumbar puncture, psychiatric disturbances, hypertension, heart block, cardiac conduction defects, arrhythmias, hypersensitivity to local anaesthetics or nalbuphine and dexmedetomidine, intake of analgesic or experimental medication within last 24 hours, head injury cases and patients receiving beta - blocker, calcium channel blocker, angiotensin converting enzyme inhibitor/ blocker, anti-arrhythmic, anti-coagulant, alpha adrenergic antagonist were excluded from the study.

Sample size calculation was done by openepi.com Assuming the duration of analgesia of $300 \mathrm{~min}[11],[12]$ and SD of 70 min keeping power at $80 \%$ and confidence interval at $95 \%$ ( $\alpha$-error at 0.05 ) a sample of 27 patients would be required to detect a minimum of $20 \%$ ( $60 \mathrm{~min}$ ) difference in the duration of analgesia between the two groups. We included 30 patients in each group to compensate for possible dropouts. Sixty patients were divided randomly into two groups of 30 each by using computer-generated random number table. Group D received $0.5 \%$ bupivacaine $(\mathrm{H}) \quad 0.8 \mathrm{~mL}+5 \mathrm{mcg}$ dexmedetomidine and group $\mathrm{N}$ received $0.5 \%$ bupivacaine $(\mathrm{H})$ $0.8 \mathrm{~mL}+0.6 \mathrm{mg}$ nalbuphine.

Patients were kept nil by mouth for 6 hours before induction of anaesthesia. On the day of surgery patients were premedicated with Inj. Ranitidine $50 \mathrm{mg}$ intravenously (IV). After shifting the patient to operation theatre, monitors like electrocardiogram (ECG), peripheral oxygen saturation (Spo2), non-invasive blood pressure (NIBP) were connected to the patient and baseline values are recorded. Intravenous line was secured with 18G / 20G cannula to start lactated Ringer's solution at five to seven $\mathrm{mL} / \mathrm{kg} / \mathrm{hr}$ rate peri-operatively.

Under aseptic precautions, lumbar puncture was done in sitting position by midline approach by using disposable Quincke's spinal needle (25G) at L3 - L4 intervertebral space and the study drug according to group was administered. The required dose of dexmedetomidine was drawn using a tuberculin syringe $(0.05 \mathrm{~mL}$ for $5 \mu \mathrm{g})$. The drug solution was made under sterile precautions by another anaesthesiologist who was not involved in administration and further monitoring of the patient. After, Subarachnoid block, the patient was made sit for 10 minutes and then made supine. Oxygen (4 Liters/minute) by Hudson mask was given. Fluid therapy was maintained with Lactated Ringers Solution (2 $\mathrm{mL} / \mathrm{kg} /$ hour) or Normal saline $(2 \mathrm{~mL} / \mathrm{kg} /$ hour $)$. HR, SBP and DBP monitored at $0,1,3,5$ minutes and at an interval of five minutes till 30 minutes and at 45, 60,120 and 180 minutes till patient requires first rescue analgesia.

The onset of sensory block was tested by pinprick using a hypodermic needle. The time of onset was taken as time required for a sensory block to reach $S_{1}$ (i.e., loss of sensation over bilateral toes) The level of the sensory block was assessed every $2 \mathrm{~min}$ after intrathecal injection till $10 \mathrm{~min}$ and every 5 min thereafter until maximum level of sensory block level achieved. Peak sensory block is defined as the highest level recorded on three consequent readings. Bromage scale ${ }^{[13]}$ was taken to assess the motor block. (grade 0 - full flexion of knees and feet, Grade 1 - just able to flex knees, full flexion of feet, grade 2 - unable to flex knees, but some flexion of feet possible, grade 3 - unable to move legs or feet).

Hypotension (more than 20\% fall in SBP from baseline) was treated with Inj. Mephentermine 6 mg. Bradycardia $(\mathrm{HR}<$
50 beats/min) was treated with Inj. Atropine. Respiratory depression ( $\mathrm{RR}<$ eight breaths/min) was treated with oxygen supplementation and respiratory support as needed. Occurrence of nausea, vomiting and shivering were recorded.

Patients and caring nurses in post-operative recovery area were instructed to notify the investigator whenever patient sensed pain in surgical site. Duration of analgesia was taken as time taken for the first pain medication was noted (i.e., VAS >4). Analgesics were administered according to surgeons' decision. Frequency of analgesics administered, time to first self -void and urinary retention requiring catheterization as per surgeons' discretion were recorded from nursing chart at $24^{\text {th }}$ hour when study period was completed.

\section{Statistical Analysis}

Statistical analysis was done by using descriptive and inferential statistics using Chi- square test and Student's t-test. Software used in the analysis was SPSS version 17.0. Data were expressed as mean, standard deviation and standard error of mean or numbers. Ordinal variables were analysed using Mann-Whitney U-test. The level of significance was $\mathrm{p}<0.05$.

\section{RESULTS}

Saddle spinal block was given to all patients and there was no rescue analgesia or general anaesthesia required during surgery. While changing the syringe for injecting the study drug, spillage of the initially administered drug was not observed. Sixty patients were evaluated, 30 patients in each group and no patient excluded at any stage of the study. The demographic data regarding age, gender distribution in study patients, weight, height and duration of surgery were similar in both the study groups [Table/Fig. 2]

\begin{tabular}{|cccc|}
\hline Patient Characteristics & Group D & Group N & P-Value \\
Age (years) & $42.0 \pm 8.64$ & $40 \pm 5.82$ & $\mathrm{p}=0.298, \mathrm{NS}$ \\
Gender (male/female) & $14 / 16$ & $11 / 19$ & $\mathrm{p}=0.43, \mathrm{NS}$ \\
Height (cm) & $155.5 \pm 7.62$ & $157.20 \pm 6.24$ & $\mathrm{p}=0.348, \mathrm{NS}$ \\
Weight (kilograms) & $54.56 \pm 6.0$ & $56.8 \pm 5.54$ & $\mathrm{p}=0.138, \mathrm{NS}$ \\
Duration of surgery & $30.42 \pm 10.5$ & $28.52 \pm 12.26$ & $\mathrm{p}=0.521, \mathrm{NS}$ \\
\hline \multicolumn{4}{|c|}{ Table/Figure 2. Demographic Data } \\
\hline
\end{tabular}

The mean onset of sensory block in Group D was $4.42 \pm$ 2.02 minutes and Group N was $4.60 \pm 1.24$ minutes with no statistical difference between the groups $(\mathrm{p}=0.416)$. There was no significant statistical difference between two groups with respect to the peak sensory block achieved (group D - L2, Group $\mathrm{N}-\mathrm{L}_{1}$ ). The mean time required for peak sensory block in Group D was 14. $26 \pm 6.62$ minutes and Group N was $13.6 \pm$ 3.42 minutes with no statistical difference between the groups ( $p=0.629$ ). Number of dermatomes blocked in Group D was 7 and in Group $\mathrm{N}$ was 6 which is statistically not significant [table/Fig. 3].

Maximum motor block achieved in Group D was Grade 0 25, Grade 1-5 and in Group N it was Grade 0-23, Grade 1-7 with no statistical difference between the groups. The mean duration of motor block in Group D was $180.0 \pm 55.42$ minutes and in Group N it was $160.50 \pm 58.24$ minutes with no statistical difference between the groups $(p=0.189)$ [Table/Fig. 3]. 


\begin{tabular}{|c|c|c|c|}
\hline Block Characteristics & Group D & Group N & P Value \\
\hline Onset of sensory block (min) & $4.42 \pm 2.02$ & $4.60 \pm 1.24$ & $0.416, \mathrm{NS}$ \\
\hline Peak sensory block achieved & $\mathrm{L}_{2}$ & $\mathrm{~L}_{1}$ & \\
\hline $\begin{array}{l}\text { Time required for peak sensory block } \\
\text { (min) }\end{array}$ & $14.26 \pm 6.62$ & $13.6 \pm 3.42$ & $0.629, \mathrm{NS}$ \\
\hline Number of dermatomes blocked & 7 & 6 & $0.10, \mathrm{NS}$ \\
\hline Maximum mc & $0-25(83.34 \%)$ & $0-23(76.67 \%)$ & 0.5 \\
\hline Bromage scal & $1-5(16$ & $1-7(23$ & \\
\hline Duration of motor block (min) & $180.0 \pm 55.42$ & $160.50 \pm 58.24$ & $0.189, \mathrm{NS}$ \\
\hline Duration of analgesia (min) & $320.26 \pm 89.52$ & $222 \pm 25.43$ & $0.000, \mathrm{~S}$ \\
\hline \multicolumn{4}{|c|}{ Table/Figure 3. Block Characteristics and Duration of Analgesia } \\
\hline
\end{tabular}

Mean duration of analgesia was more in Group D (320.26 \pm 89.52 minutes) compared to Group N (222 \pm 25.43 minutes $)$, which was statistically significant $(\mathrm{p}=0.000)$ [table/Fig. 3].

Both the groups were comparable throughout the study period with respect to mean heart rate and mean arterial blood pressure, however, dexmedetomidine group showed better hemodynamic stability when compared to nalbuphine group. [table/fig. 4] There was no significant drug related side effects like hypotension, bradycardia, pruritis were observed.

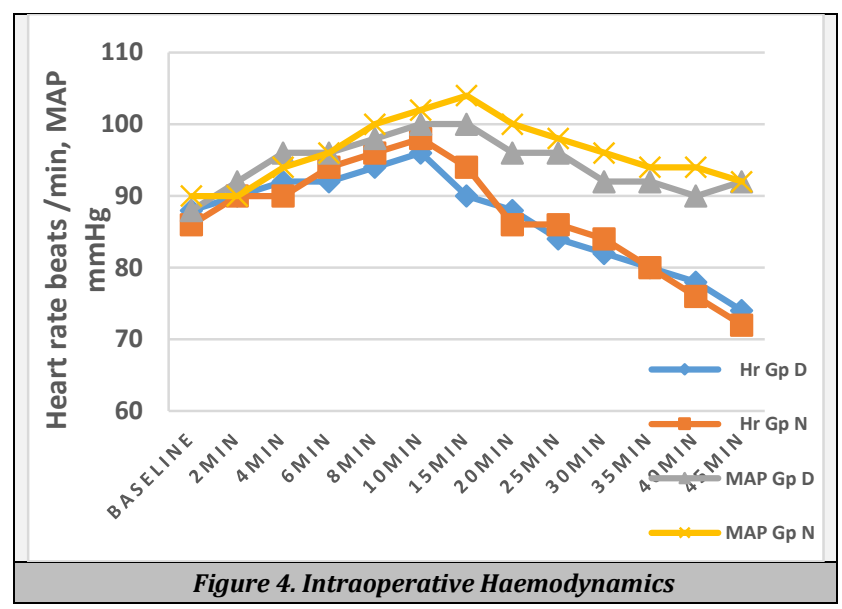

${ }^{*} \mathrm{Hr}$ Gp D - heart rate of group dexmedetomidine, Hr Gp N - heart rate of group nalbuphine, MAP Gp D - mean arterial pressure of group dexmedetomidine, MAP Gp N - mean arterial pressure of group nalbuphine.

\section{DISCUSSION}

Effective post-operative pain control has become mandatory for optimum care of patients nowadays. Saddle spinal block is a simple technique which uses local anaesthetics in small doses and provides required surgical anaesthesia, muscle relaxation and analgesia. Dexmedetomidine five micrograms as an adjuvant to $0.5 \%$ hyperbaric bupivacaine $0.8 \mathrm{~mL}$ in saddle spinal block was found significantly prolong duration of analgesia and therefore significant analgesic requirement reduction was observed. The present study design consisted of 60 patients aged between 20-60 years, ASA physical status l, ll undergoing elective perianal surgeries under saddle spinal block and were randomly divided into two groups with each group having 30 patients. Mean onset of sensory block, peak sensory block, time to peak sensory block, number of dermatomes blocked, maximum motor block and duration of motor block in Group D and Group N are comparable with no statistical difference between the two groups. Similarly, Binod Gautam et al.,[11] also found that the mean onset of sensory block with bupivacaine + dexmedetomidine was $4.61 \pm 1.75$ minutes, time to peak sensory block was $15.55 \pm 5.29$ minutes, number of dermatomes blocked was 8 (5-12), maximum motor block was Bromage scale grade 0 in 16 patients, grade 1 in 5 patients, grade 2 in 2 patients and duration of motor block was $187.50 \pm 55.67$ minutes which was comparable with the present study. Similarly, Jyothi et al.,[14] found that the onset of sensory block was faster in bupivacaine with nalbuphine compared to bupivacaine alone.

Sudheesh et al.,[15] compared two doses of intrathecal dexmedetomidine as adjuvant to hyperbaric bupivacaine for saddle block in ambulatory perianal surgeries and found that onset of sensory block was faster with 5 micrograms compared to 3 micrograms of dexmedetomidine. Duration of motor block was $196.14 \pm 84.28 \mathrm{~min}$ in Sudheesh et al., study which was comparable with the present study.

Kataria AP et al.,[16] compared the intrathecal nalbuphine versus ketamine with hyperbaric bupivacaine in lower abdominal surgeries and found that onset of sensory block was faster with bupivacaine + nalbuphine compared to bupivacaine + ketamine, but in our study we observed that onset of sensory block was faster with bupivacaine + dexmedetomidine compared to bupivacaine + nalbuphine with no significant statistical difference. Kataria AP et al., also observed that the duration of motor block with bupivacaine + nalbuphine was $148.87 \pm 6.80$ minutes which was comparable to the present study.

Gupta KL et al.,[17] conducted study to know the efficiency of nalbuphine as an adjuvant to bupivacaine in lower limb orthopaedic surgeries and observed that the onset of sensory block was faster with bupivacaine + nalbuphine compared to bupivacaine + normal saline but the observed result was comparable with the present study.

Shagufta Naaz et al.,[18] conducted comparative study of analgesic effect of intrathecal nalbuphine and fentanyl as adjuvant with hyperbaric bupivacaine in lower limb orthopaedic surgeries and observed that time required to reach peak sensory level was $9.8 \pm 4.15$ minutes with bupivacaine + nalbuphine which was comparable to present study. Similarly, Shagufta Naaz et al., also found that the duration of motor block was $177.5 \pm 50.45$ minutes with bupivacaine + nalbuphine which was comparable with the present study. Above mentioned studies were done with nalbuphine 0.8 milligram but in the present study we have used nalbuphine 0.6 milligram. However, the results obtained in our study were comparable with the above-mentioned studies.

Regression of sensory block was not studied as it was anticipated that the pain around operated site and analgesic request for the same would be clinically more important. Additionally, frequent sensory assessments around private parts could substantiate the patient harassment.

The mean duration of analgesia is more in Group D compared to group $\mathrm{N}$, which was statistically significant. Similar results were obtained by Binod Gautam et al.,[11] also found that the mean duration of analgesia was longer in group bupivacaine + dexmedetomidine with $501.35 \pm 306.46$ minutes compared to the group bupivacaine with $284.24 \pm$ 58.38 minutes, which was statistically significant. Similar results were obtained by Jyothi B et al.,[14] found that the mean duration of analgesia was longer in group bupivacaine + 
nalbuphine (0.8 milligrams) with $322.4 \pm 31.1$ minutes, which was statistically significant. Similarly, Sudheesh et al.,[15] was also found that the mean duration of analgesia was longer in group bupivacaine + dexmedetomidine ( 5 micrograms) with $167.85 \pm 93.75$ minutes compared to the group bupivacaine + dexmedetomidine (3 micrograms). Prasanna et al.,[12] was also observed that the mean duration of analgesia in group bupivacaine + nalbuphine (0.8 milligrams) was $247.38 \pm 12.2$ minutes. Even though, Jyothi B et al., [14] and Prasanna et al.,[12] conducted studies with nalbuphine 0.8 milligram it was comparable with the present study where we have used nalbuphine 0.6 milligram. Binod Gautam et al.,[11] and Sudheesh et al.,[15] studies were comparable with the present study as in both cases dexmedetomidine 5 micrograms were used.

\section{Mechanism of Action of Dexmedetomidine with Respect to Analgesic Effect}

Dexmedetomidine is highly selective $\alpha_{2}$-Adrenoceptor agonist, when co-administered intrathecally with bupivacaine results in binding to presynaptic C-fibers and post-synaptic dorsal horn nucleus in spinal cord which results in synergistic action to the local anaesthetics effects. The resulting effect may be related to the drug lipophilicity.[19],[20]

\section{Mechanism of Action of Nalbuphine with Respect to Analgesic Effect}

Nalbuphine semi-synthetic opioid with agonist at kappa receptor and antagonist at mu receptor. It activates caudate perhaps by disinhibition and initiates pain enhancing connectivity with other regions. Pronociceptive effect of nalbuphine is abolished by blockade of this connectivity. [21]

Both the groups were comparable throughout the study period with respect to mean heart rate and mean arterial blood pressure. Similar results were cited by other researchers also comparable with the present study.[12],[15] There was no significant drug related side effects like hypotension, bradycardia, respiratory depression and pruritis were observed.

Saddle spinal block was found to be excellent in perianal surgeries as pain around anal region is intense and reflexogenic. So, perianal surgeries require deep levels of anaesthesia. Saddle spinal block also avoided hypotension and bradycardia in our study. It does not require specific skill and appliances. Intensive monitoring was also not required due to lack of serious side effects.[11] Future research will be better to clarify the potential to reduce local anaesthetic dose requirement amongst appropriate surgical population and dose related effects to dexmedetomidine and nalbuphine.

\section{Limitations}

Sedation score was not assessed in case of dexmedetomidine group as the drug dosage we used in the present study is minimal. Side effects were not considered in both dexmedetomidine and nalbuphine group as minimal dosage of the drug was used in the present study.

\section{CONCLUSIONS}

A dose of 5 mcg dexmedetomidine as an adjuvant seems to be optimal for providing postoperative analgesia with better haemodynamic stability.

\section{REFERENCES}

[1] Gudaityte J, Marchertiene I, Karbonskiene A, et al. Lowdose spinal hyperbaric bupivacaine for adult anorectal surgery: a double-blinded, randomized, controlled study. J Clin Anesth 2009;21(7):474-81.

[2] Kim JE, Kim NY, Lee HS, et al. Effects of intrathecal dexmedetomidine on low-dose bupivacaine spinal anesthesia in elderly patients undergoing transurethral prostatectomy. Biol Pharm Bull 2013;36(6):959-65.

[3] Awad IT, Cheung JJH, Al-Allaq Y, et al. Low-dose spinal bupivacaine for total knee arthroplasty facilitates recovery room discharge: a randomized controlled trial. Can J Anesth 2013;60(3):259-65.

[4] Rao ST, Khanooja S. A comparison of intrathecal bupivacaine with fentanyl to bupivacaine alone for elective caesarian section. Paripex-Indian Journal of Research 2013;2(7):204-6.

[5] Bakshi U, Chatterjee S, Sengupta S, et al. Adjuvant drugs in central neuraxial analgesia-a review. Internet Journal of Anesthesiol 2009;26(1).

[6] Bhana N, Goa KL, McClellan KJ. Dexmedetomidine. Drugs 2000;59(2):263-8.

[7] Mostafa MG, Mohamad MF, Farrag WS. Which has greater analgesic effect: intrathecal nalbuphine or intrathecal tramadol. J Am Sci 2011;7:480-4.

[8] Gunion MW, Marchionne AM, Anderson CTM. Use of the mixed agonist-antagonist nalbuphine in opioid based analgesia. Acute Pain 2004;6(1):29-39.

[9] Culebras X, Gaggero G, Zatloukal J, et al. Advantages of intrathecal nalbuphine, compared with intrathecal morphine, after cesarean delivery: an evaluation of postoperative analgesia and adverse effects. Anesth Analg 2000;91(3):601-5.

[10] Tiwari AK, Tomar GS, Agrawal J. Intrathecal bupivacaine in comparison with a combination of nalbuphine and bupivacaine for subarachnoid block: a randomized prospective double-blind clinical study. Am J Ther 2013;20(6):592-5.

[11] Gautam B, Lama SM, Sharma M. Effects of adding intrathecal dexmedetomidine to hyperbaric bupivacaine for saddle spinal block in adults undergoing peri-anal surgeries. J Nepal Health Res Council 2018;16(1):43-8.

[12] Vadhanan $P$, Balakrishnan K. Comparison of postoperative analgesia with $0.8 \mathrm{mg}$ and $1.6 \mathrm{mg}$ intrathecal nalbuphine; a randomized controlled trial. Anaesth Pain \& Intensive Care 2019;21(1):37-43.

[13] Gantasala BV, Singam A, Taksande K. Bupivacaine (0.5\%) versus $(0.5 \%)$ bupivacaine with ketamine $(50 \mathrm{mg}$ ) for subarachnoid block in lower abdominal surgeries: a randomised comparative study. J Clin Diagn Res 2019;13(3):16-9. 
[14] Jyothi B, Gowda S, Shaikh SI. A comparison of analgesic effect of different doses of intrathecal nalbuphine hydrochloride with bupivacaine and bupivacaine alone for lower abdominal and orthopedic surgeries. Indian J Pain 2014;28(1):18-23.

[15] Sudheesh K, Rao RR, Kavya M, et al. Comparative study of two doses of intrathecal dexmedetomidine as adjuvant with low dose hyperbaric bupivacaine in ambulatory perianal surgeries: a prospective randomised controlled study. Indian J Anaesth 2015;59(10):648-52.

[16] Kataria AP, Singh H, Mohan B, et al. Intrathecal nalbuphine versus ketamine with hyperbaric bupivacaine in lower abdominal surgeries. Anesth Essays Res 2018;12(2):366-70.

[17] Gupta KL, Gupta A, Neeraj. Efficiency of nalbuphine as an adjuvant to bupivancaine in lower limb orthopaedic surgery-a prospective study. Int J Res Med Sci 2017;5(2):623-6.

[18] Naaz S, Shukla U, Srivastava S, et al. A comparative study of analgesic effect of intrathecal nalbuphine and fentanyl as adjuvant in lower limb orthopaedic surgery. J Clin Diagn Res 2017;11(7):UC25-8.

[19] Eisenach JC, Shafer SL, Bucklin BA, et al. Pharmacokinetics and pharmacodynamics of intraspinal dexmedetomidine in sheep. Anesthesiology 1994;80(6):1349-59.

[20] Ishii H, Kohno $\mathrm{T}$, Yamakura $\mathrm{T}$, et al. Action of dexmedetomidine on the substantia gelatinosa neurons of the rat spinal cord. Eur J Neurosci 2008;27(12):318290.

[21] Gear R, Becerra L, Upadhyay J, et al. Pain facilitation brain regions activated by nalbuphine are revealed by pharmacological fMRI. PLoS One 2013;8(1):e50169. 